\title{
RESTORATION OF AQUATIC PLANTS AFTER EXTREME FLOODING AND DROUGHT: A CASE STUDY FROM POYANG LAKE NATIONAL NATURE RESERVE
}

\author{
ZHANG, X. K. ${ }^{1,2}-$ LIU, X. Q. ${ }^{1 *}-$ YANG, Z. D. ${ }^{1}-$ WANG, H. Z. ${ }^{1}$ \\ ${ }^{1}$ Institute of Hydrobiology, Chinese Academy of Sciences, Wuhan 430072, China \\ ${ }^{2}$ Research Center of Aquatic Organism Conservation and Water Ecosystem Restoration in \\ University of Anhui Province, Anqing Normal University, Anqing 246133, China \\ ${ }^{*}$ Corresponding author \\ e-mail:xqliu@ihb.ac.cn
}

(Received 21 $1^{\text {st }}$ Aug 2019; accepted $31^{\text {st }}$ Oct 2019)

\begin{abstract}
Poyang Lake is the largest freshwater lake in China. Extreme flooding and drought occurred in 1998 and 2011, respectively, resulting in a massive loss of aquatic plants. To compare the effects of flooding and drought on aquatic plants and the subsequent recovery process, field investigations were conducted in Poyang Lake National Nature Reserve (PLN) in 2012 and 2014. Historical data from 1984, 1999, and 2001 were also used for comparison. The results revealed that the species composition of aquatic plants after extreme flooding differed from that after extreme drought. After flooding, the species composition was basically the same as the historical records from 1984 under normal hydrological conditions; however, after drought, Najas marina and N. minor disappeared. Moreover, the resilience ability of aquatic plants was higher after extreme flooding than following extreme drought. The dominant species also differed after the two hydrological events. Vallisneria spp. and Hydrilla verticillata were first to recover after flooding, while Vallisneria spp. and Nymphoides peltata recovered fastest after drought. Since extreme drought is more damaging to aquatic vegetation than extreme flooding, we suggest that lakes in the Yangtze River basin aim to maintain a minimum water level through rational regulation of water resources.
\end{abstract}

Keywords: macrophytes, extreme hydrological events, ecological restoration, resilience ability, regulation

\section{Introduction}

Natural interference is an essential component of most intact ecosystems (Lytle and Poff, 2004). Flooding and drought, as the main disturbances affecting freshwater ecosystems, play important roles in regulating aquatic plant diversity and population size across a range of spatial and temporal scales (Jentsch et al., 2007; Lake, 2007). Under natural conditions, aquatic plants have adapted to periodic flooding and drought through morphological or life-history strategical changes (Lytle and Poff, 2004). However, anthropogenic disturbances (such as overuse of water resources, and building of sluices and dams) and climate change are severely affecting the periodic rhythms of flooding and drought, increasing the occurrence frequency and magnitude in many freshwater ecosystems (Meehl et al., 2007; Miao et al., 2009). Non-periodic high-intensity extreme hydrological events can severely destroy the ecosystem structure of wetland environments, altering the natural habitat conditions required by aquatic plants ( $\mathrm{Li}$ et al., 2004; Lake, 2007). However, studies on aquatic plants in freshwater lakes tend to focus on the effects of water depth, rates of water level change, fluctuation amplitude, and fluctuation duration, with little known about the impact of extreme hydrological events such as flooding and drought, and subsequent restoration and succession. 
Poyang Lake (N: $28^{\circ} 22^{\prime}-29^{\circ} 45^{\prime}$, E: $115^{\circ} 47^{\prime}-116^{\circ} 45^{\prime}$ ) is the largest freshwater lake in China, located on the south bank of the Yangtze River in Jiangxi Province. It is an internationally important wetland, and one of three river-connected lakes in the middle and lower Yangtze River. Poyang Lake mainly collects water from five rivers, the Ganjiang, Xiushui, Raohe, Fuhe and Xinjiang River, flowing into the Yangtze River in Hukou County (Figure 1). In the flooding season, when the water level in the Yangtze River is higher than that of Poyang Lake, water flows back into the lake. The perennial average water level of Poyang Lake is $12.86 \mathrm{~m}$ above mean sea level (amsl), but the annual variation can exceed $10 \mathrm{~m}$ ( $\mathrm{Li}$ et al., 2008). The surface area also differs significantly between flooding and drought periods, from $2933 \mathrm{~km}^{2}$ at a flood water level of $21.69 \mathrm{~m}$ amsl to only $146 \mathrm{~km}^{2}$ at a water level of $10.20 \mathrm{~m}$ amsl (Wang and Dou, 1998). Because of this unique hydrological rhythm, Poyang Lake consists of diverse habitats with high species diversity, and enormous ecological and service functions. However, due to the impact of climate change and the Three Gorges Reservoir, extreme hydrological events have occurred frequently during the past few decades (Xu et al., 2014), the most serious of which were the extreme floods of 1998 and extreme drought of 2011.

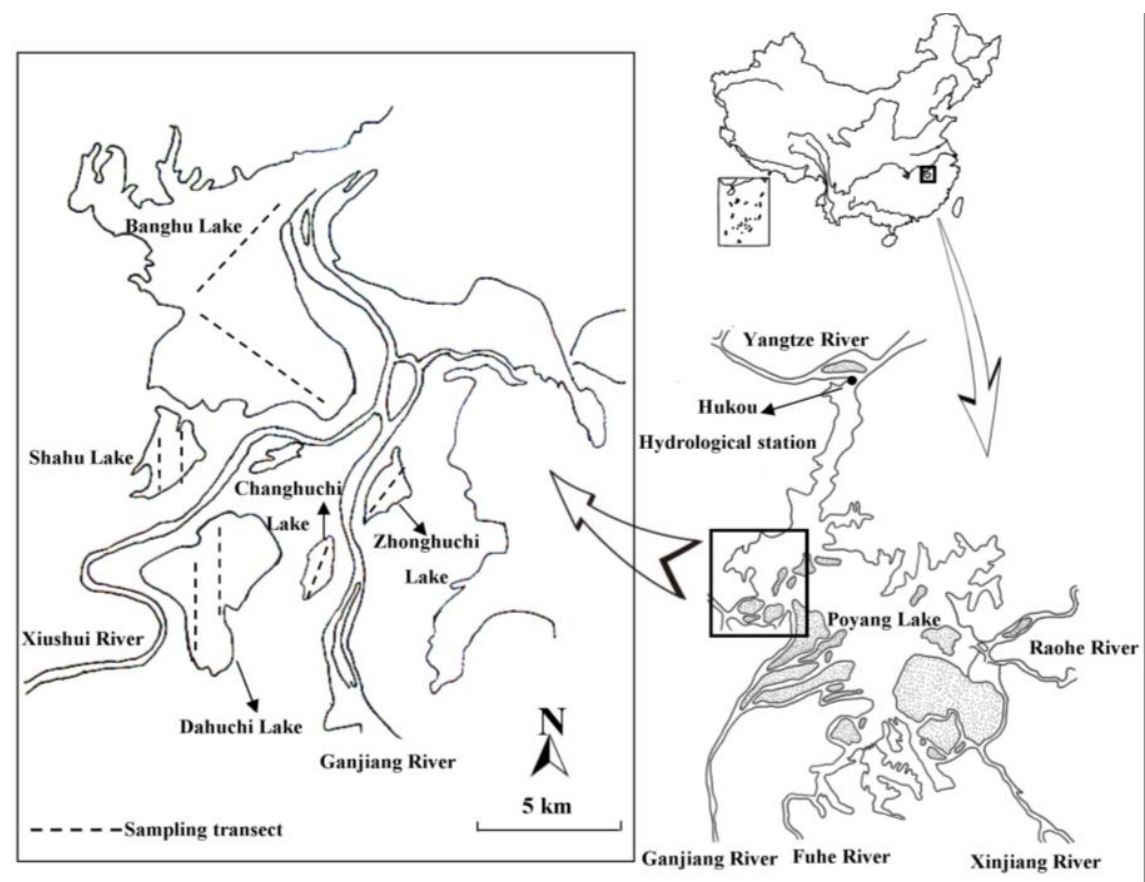

Figure 1. Sampling transects in PLN

Poyang Lake National Nature Reserve (PLN) is located northwest of Poyang Lake, and is mainly composed of sub-lakes with differing mean lake bottom elevations. In this study, we selected five sub-lakes (Figure 1) in PLN and, combined with historical data, determined the following: 1) The difference in community structure and resilience ability of aquatic plants in PLN following extreme flooding and extreme drought; and 2) Differences in the resilience ability of aquatic plants in the five sub-lakes with increasing mean lake bottom elevation. Since flooding and drought have differing effects on aquatic plants, the former largely affecting aboveground parts and the latter acting both aboveground and underground, we hypothesized that the community 
structure would also differ after each hydrological event, with greater resilience after flooding. In addition, since under normal circumstances, increasing distribution elevation gradually weakens the impact of flooding, while increasing that of drought, we further hypothesized that aquatic plants in sub-lakes with a higher mean lake bottom elevation would show stronger resilience ability after flooding than drought. The results of this study not only enrich our understanding of extreme hydrological events, but also have significant implications for the restoration of aquatic plants in other lakes with similar situations.

\section{Materials and methods}

\section{Research area}

PLN (N: $28^{\circ} 22^{\prime}-29^{\circ} 45^{\prime}$, E: $115^{\circ} 47^{\prime}-116^{\circ} 45^{\prime}$ ) was established in 1983 and listed in the International List of Wetlands in 1992, forming the main habitat for a number of rare animals and plants (Ji et al., 2007). It has a subtropical monsoon climate with an average annual temperature of $17.1^{\circ} \mathrm{C}$ and average annual rainfall of $1426.4 \mathrm{~mm}$. The protected area of PLN covers $224 \mathrm{~km}^{2}$, and is mainly composed of nine sub-lakes with differing mean lake bottom elevations (Figure 1, Table 1). When the water level in the main area of Poyang Lake is higher than $16.0 \mathrm{~m}$ amsl, all these sub-lakes merge into Poyang; however, when the water level is less than $12.92 \mathrm{~m}$ amsl, these sub-lakes gradually emerge and become independent lakes (Li et al., 2004).

Table 1. Area, bottom elevation and sampling transects in the five sub-lakes in PLN. Bottom elevation data was obtained from Lu and Cheng (2003). All other data were from Zhang (2013)

\begin{tabular}{c|c|c|c|c|c}
\hline Item & Banghu & Zhonghuchi & Changhuchi & Dahuchi & Shahu \\
\hline Area $\left(\mathrm{km}^{2}\right)$ & 73 & 6 & 7 & 30 & 14 \\
Maximum length $(\mathrm{km})$ & 10.08 & 3.84 & 3.70 & 7.43 & 4.46 \\
Maximum width (km) & 8.04 & 1.82 & 2.22 & 4.36 & 3.48 \\
Mean water depth (m) & 0.46 & 1.07 & 0.50 & 0.70 & 0.45 \\
Bottom elevation (m) & 12.6 & 13.5 & 14.5 & 14.7 & 15.1 \\
$\begin{array}{c}\text { Total nitrogen content of the } \\
\text { substrate (mg/g) }\end{array}$ & 0.68 & 1.08 & 1.17 & 0.68 & 1.33 \\
$\begin{array}{c}\text { Total phosphorus content of } \\
\text { the substrate (mg/g) }\end{array}$ & 0.68 & 0.66 & 0.74 & 0.62 & 0.92 \\
$\begin{array}{c}\text { Organic matter content of the } \\
\text { substrate (\%) }\end{array}$ & 20.88 & 28.93 & 28.94 & 19.88 & 33.93 \\
$\begin{array}{c}\text { Number of sampling transects } \\
\text { (sites) }\end{array}$ & $2(12)$ & $1(10)$ & $1(4)$ & $2(11)$ & $2(11)$ \\
\hline
\end{tabular}

In 1998 and 2011, Poyang Lake experienced the most serious flooding (Min et al., 2006) and drought (Li et al., 2019) events in nearly 60 years, respectively (Figure 2). In the summer of 1998, the water level of Poyang Lake reached a maximum of $22.54 \mathrm{~m}$, and remained higher than warning level for 58 consecutive days. Following this extreme hydrological event, almost all aquatic plants in the nine sub-lakes were reported extinct (Li et al., 2004). Subsequently, in the spring of 2011, Poyang Lake remained at a consistently low level, causing all nine sub-lakes (except Banghu Lake) to dry up, seriously damaging the aquatic plant populations. 


\section{Sampling method and data analyses}

In July 2012 and June 2014, following the extreme drought of 2011, analysis of the aquatic vegetation in five sub-lakes was carried out; namely, Banghu, Dahuchi, Zhonghuchi, Changhuchi and Shahu lakes. According to differences in lake area (Table 1), 1-2 sampling transects were set in each sub-lake, and in each sampling transect, 4-10 sampling sites were established (Figure 1). Aquatic plant populations were quantitatively sampled using a scythe three times in each site. Samples were then cleaned and superfluous water removed before weighing using an electronic balance to determine wet biomass. In this study, aquatic plants only included submerged and floating macrophytes, not hygrophytes and emergent macrophytes.

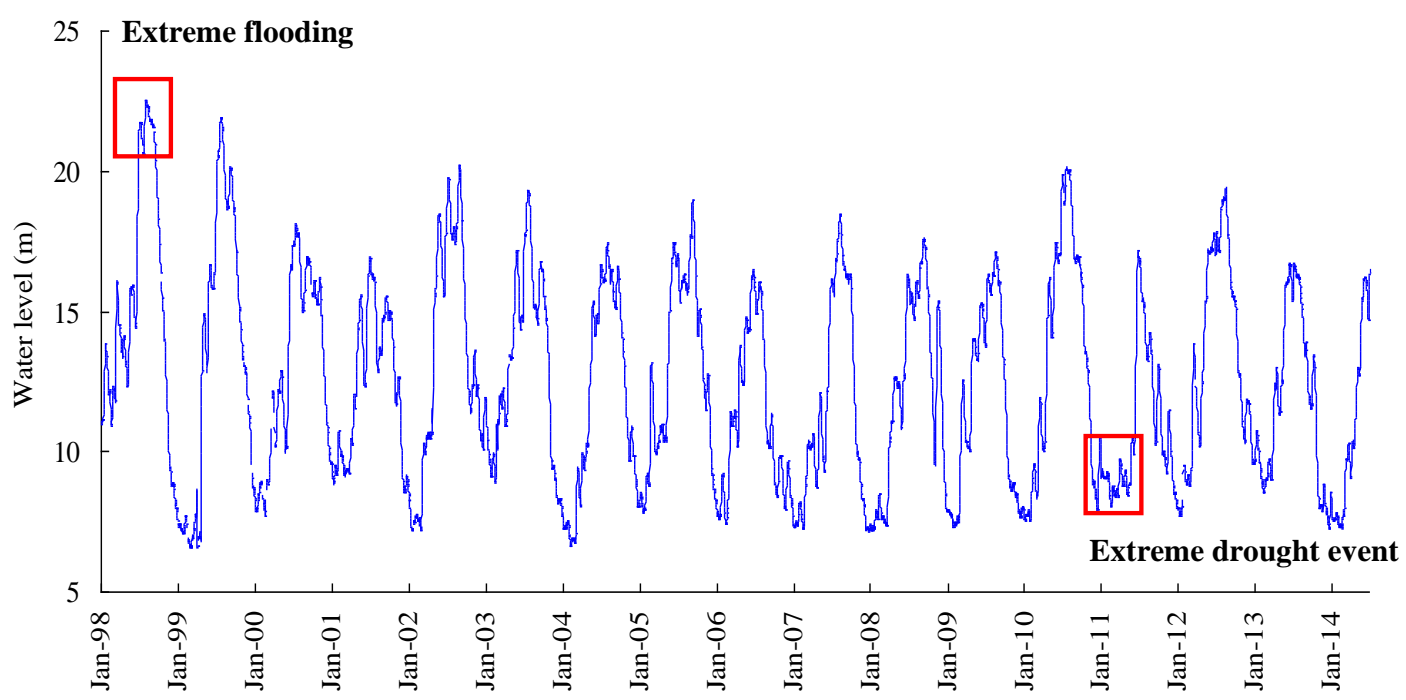

Figure 2. Water level fluctuations in Poyang Lake from 1998 to 2014

Hydrological data for 1998 to 2014 were obtained from Hukou Hydrological Station of Poyang Lake and from the Hubei Province Water and Rain Information Inquiry System (http://219.140.162.169:8800/rw4/report/fa02.asp). Aquatic vegetation data for PLN in 1984 (normal hydrological year), 1999 and 2001 (after flooding), and 2012 and 2014 (after drought) were used for comparative analyses. Data for 1984 were obtained from Guan et al. (1987) and, since the scope of his investigation covered entire Poyang Lake, were corrected to represent PLN area. Data for 1999 and 2001 were derived from Li et al. (2004), and corrected by removing the hygrophyte and emergent plant data. All the five field investigations were conducted during summer to early autumn, and the sampling methods were similar. Therefore, the results of different investigations are comparable and can reflect the actual situation of aquatic plants in PLN in different periods. One-way analysis of variance (ANOVA) was used to analyze the difference of species number and biomass among 1999, 2001, 2012, and 2014. Before conducting the ANOVA, the normality and homogeneity of the variances were tested, and transformed if necessary to meet the assumption of ANOVA. Post-hoc multiple comparisons were conducted to examine the differences between groups using Tukey's HSD (Honestly Significant Difference) multiple comparisions. Due to the lack of occurrence frequency data for each aquatic plant in PLN at different times, this study used relative biomass to 
calculate the dominance of each species. The resilience ability of each aquatic plant in different years following each extreme hydrological event was determined using the following formula (Eq.l):

$$
R_{i}=\frac{B_{i}}{B_{h}} \times \frac{N_{i}}{N_{h}}
$$

where $R_{i}$ indicates the resilience ability in the $\mathrm{i}$-th year, $B_{i}$ indicates the aquatic plant biomass in the $i$-th year, $B_{h}$ indicates historical data of aquatic plant biomass in a normal hydrological year, $N_{i}$ indicates the species number of aquatic plants in the $i$-th year, and $N_{h}$ indicates historical data of species number in a normal hydrological year. Both $B_{h}$ and $N_{h}$ values in this study represent historical data from 1984. All data analyses were carried out using SPSS version 13.0.

\section{Results}

\section{Species composition}

In 2012 and 2014, the species composition in PNL was the same, with eight genera and eight species (Table 2). However, in 2012, all species, except Vallisneria spp. were only sporadically found. Meanwhile, in 2014, the occurrence frequency of Nymphoides peltata and Trapa spp. markedly increased. Compared to the normal hydrological year of 1984 (Table 2), the species composition was notably different after the droughts of 2012 and 2014, with the disappearance of Najas marina and N. minor, and emergence of Charaphyte. Meanwhile, the species composition following the flood in 2001 was basically the same as that in 1984, with the emergence of only one species, Charaphyte.

Table 2. Species composition and biomass $\left(\mathrm{g} / \mathrm{m}^{2}\right)$ in PLN

\begin{tabular}{c|c|c|c|c|c}
\hline Species & $\mathbf{1 9 8 4}$ & $\mathbf{1 9 9 9}$ & $\mathbf{2 0 0 1}$ & $\mathbf{2 0 1 2}$ & $\mathbf{2 0 1 4}$ \\
\hline Charaphyte & & 0.1 & 43.9 & 0.1 & 0.2 \\
Vallisneria spp. & 840.3 & 159.8 & 944.5 & 58.9 & 100.8 \\
Hydrilla verticillata & 514.7 & 139.3 & 742.7 & 8.4 & 38.6 \\
Potamogeton malaianus & 796.3 & 0.5 & 25.26 & 2.4 & 2.3 \\
Potamogeton pectinatus & & 8.2 & & & \\
Najas minor & 119.7 & 0.1 & 12.4 & & 119.8 \\
Najas marina & 11.3 & & 1.0 & & 100.1 \\
Nymphoides peltata & 134.7 & 1.0 & 0.7 & 39.5 & 34.8 \\
Trapa spp. & 93 & 18.0 & 31.7 & 9.3 & 2.5 \\
Ceratophyllum demersum & 307.7 & & 0.8 & 0.8 & 0.1 \\
Myriophyllum pectinatus & 84.3 & & 34.8 & & \\
\hline
\end{tabular}

In 1999, after the flood in 1998, the number of aquatic plant species in Banghu, Zhonghuchi, Changhuchi, Dahuchi and Shahu lakes was 3, 5, 3, 3 and 4, respectively (Figure 3). In 2001, the species number in all sub-lakes, except Zhonghuchi, and the entire PLN region increased significantly. In 2012, after the drought of 2011, the number of aquatic plant species in the five sub-lakes was 7, 1, 3, 2 and 3, respectively. 
Meanwhile, in 2014, an obvious increase in species number was observed in Zhonghuchi, Changhuchi, and Shahuchi Lakes only (Figure 3). However, ANOVA analysis showed that the species number did not have significant difference among the four years $(F=1.327, P=0.300)$.

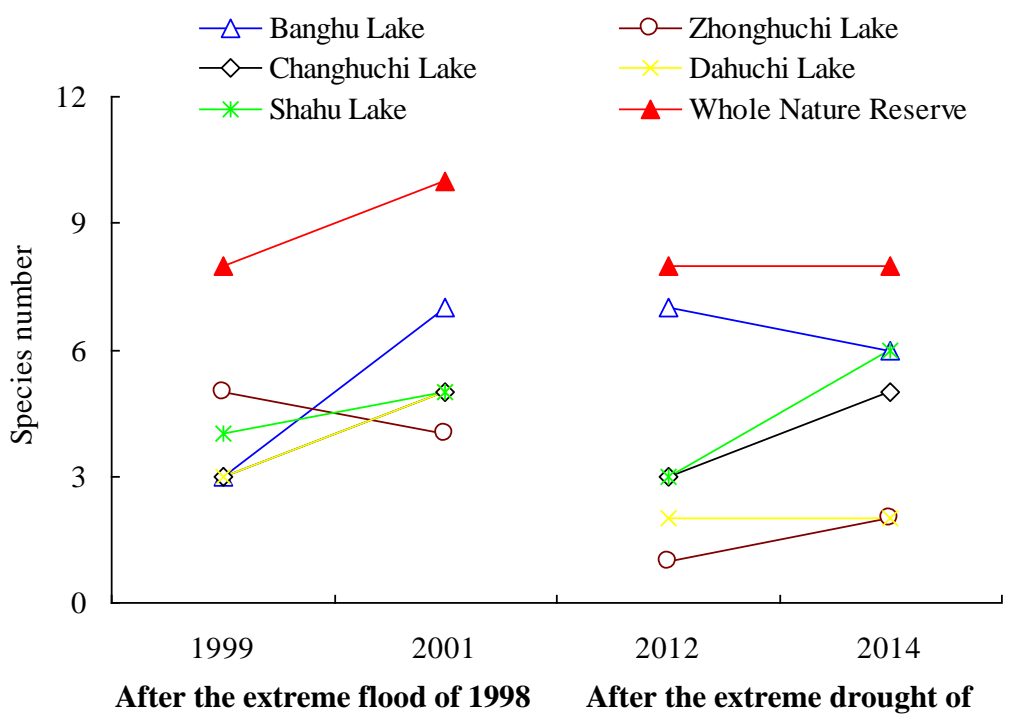

Figure 3. Changes in species numbers after extreme flooding (1998) and drought (2011) in five sub-lakes in PLN

\section{Biomass}

The biomass of aquatic plants in PLN was low in 1999 and 2012 at 327 and 120 $\mathrm{g} / \mathrm{m}^{2}$, respectively, while in 2001 and 2014, biomass was restored to 1838 and $391 \mathrm{~g} / \mathrm{m}^{2}$, respectively, although both values were obviously lower than that in $1984\left(2902 \mathrm{~g} / \mathrm{m}^{2}\right)$ (Figure 4). ANOVA analysis indicated that the biomass has significant difference among the four years $(F=8.545, P=0.001)$, and the biomass in 2001 was significantly higher than in the other three years. Of the five sub-lakes, Banghu and Zhonghuchi lakes recovered fastest after flooding, reaching a biomass of 2454 and $2534 \mathrm{~g} / \mathrm{m}^{2}$ in 2001, respectively. In 2014, following drought, the biomass of aquatic plants in each sub-lake was low, with a maximum value of $782 \mathrm{~g} / \mathrm{m}^{2}$ in Zhonghuchi Lake (Figure 5).

Vallisneria spp. and Hydrilla verticillata recovered fastest after flooding, and in 2001, their biomass exceeded historical levels (Table 2). Meanwhile, Vallisneria spp. and Nymphoides peltata recovered fastest after drought, but their biomass remained lower than historical levels (Table 2). Potomageon malaianus had the highest historical biomass, but recovered slowly after both drought and flooding, and had a very low biomass.

\section{Dominant species}

Differences in the dominant species in PLN were observed between years (Figure 6). In 1984, the main dominant species were Vallisneria spp. and P. malaianus, while in 1999 and 2001 Vallisneria spp. and H. verticillata were dominant. In 2012, the dominant species were Vallisneria spp. and N. peltata, while in 2014, Trapa spp. as well as Vallisneria spp. and $N$. peltata dominated. 


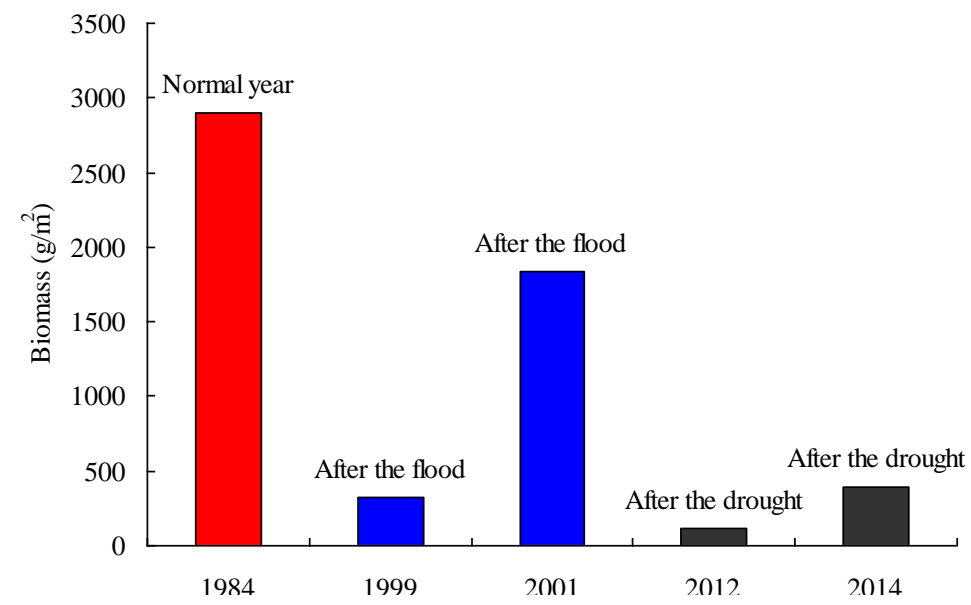

Figure 4. Comparisons of macrophyte biomass after extreme flooding and drought in PLN

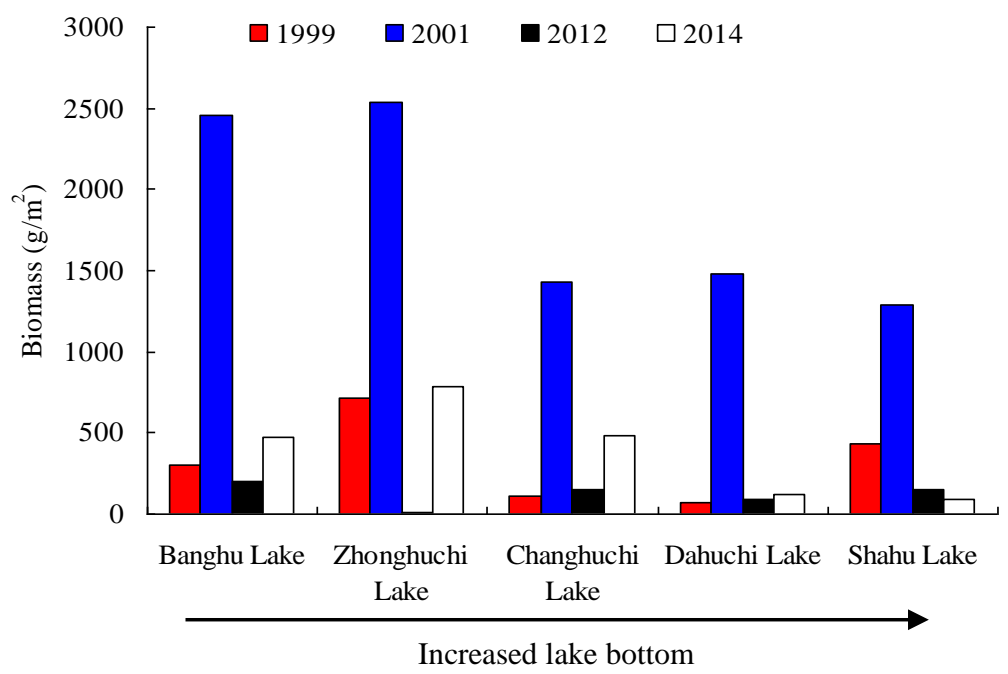

Figure 5. Comparisons of macrophyte biomass in five sub-lakes in PLN

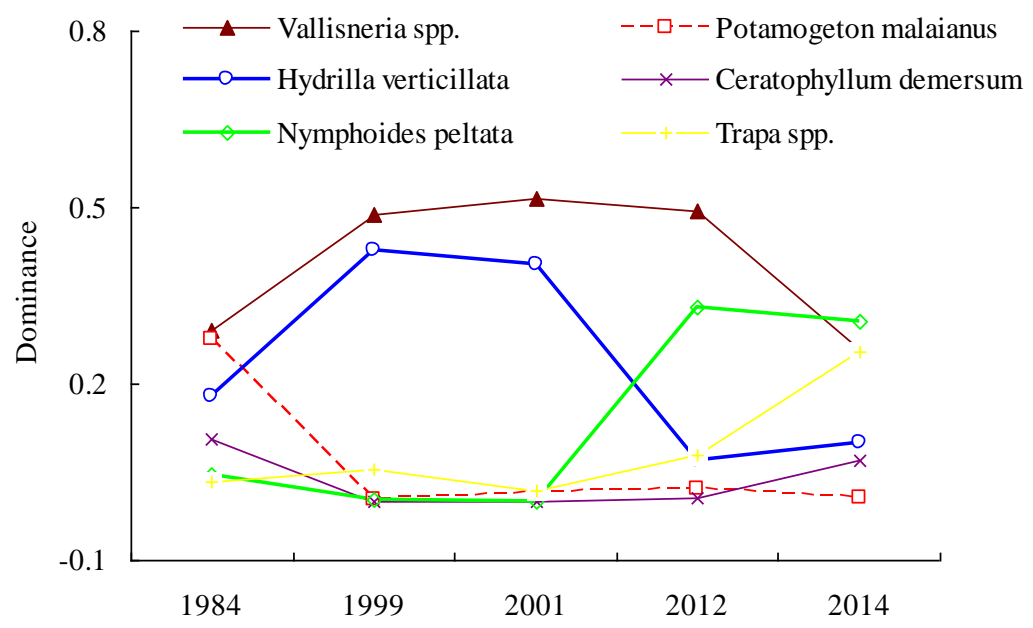

Figure 6. Changes in the dominance of different species in PLN. Only species with a dominance $>0.1$ in one of the five study years are shown 


\section{Resilience ability}

In 1999, 2001, 2012 and 2014, the resilience ability of aquatic plants in PLN was $0.10,0.70,0.04$ and 0.12 , respectively. Aquatic plants apparently showed greater resilience ability after flooding than drought. No obvious differences in resilience ability were observed with increasing bottom elevation of the sub-lakes (Figure 7). The largest resilience ability was observed in Zhonghuchi (0.14) and Banghu lakes (0.66) in 1999 and 2001, respectively. Meanwhile, in 2012 and 2014, Banghu Lake showed the largest resilience ability at 0.05 and 0.11 , respectively.

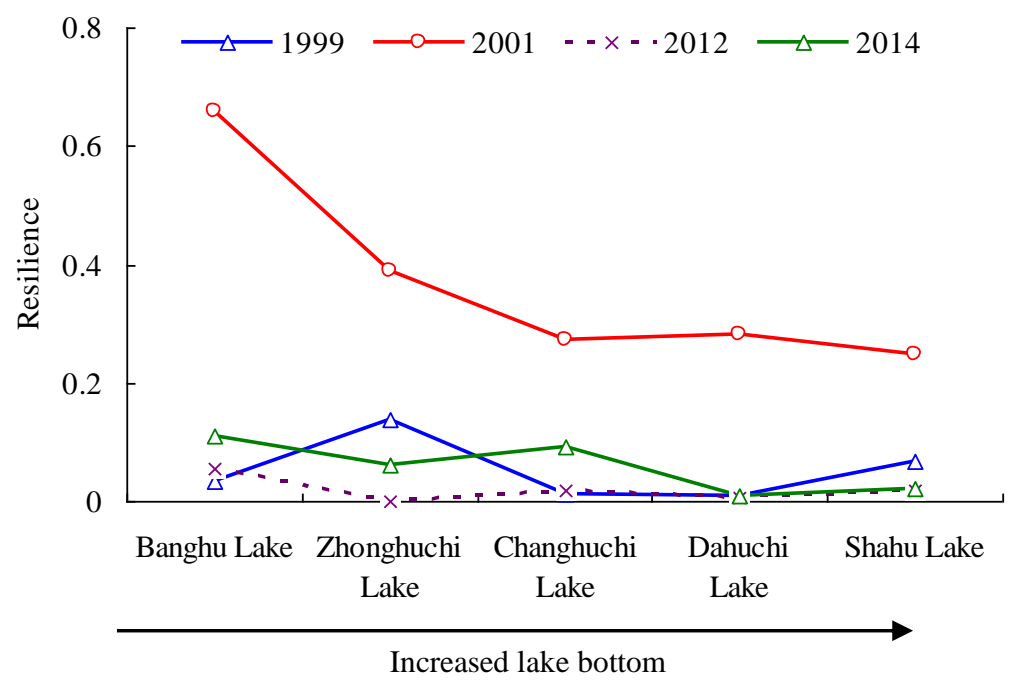

Figure 7. Resilience ability of aquatic plants in each sub-lake in PLN

\section{Discussion}

The increasing frequency and magnitude of extreme hydrological events are highlighting the negative effects on freshwater ecosystems (Jentsch et al., 2007). The results of this study suggest that drought has a greater impact than flooding on the species composition of aquatic plants. In PLN, the species composition after flooding was basically the same as that in 1984, while after drought, $N$. marina and $N$. minor disappeared. Both species are annuals, germinating in March-April, flowering and fruiting in July and August, and mainly propagated by seed. The aboveground stems are fragile and easily broken in turbulent water (Chen, 1984). Moreover, their roots are largely fibrous, and grow poorly in soil with high viscosity (Handley and Davy, 2005; Hoffmann et al., 2013). The sediment is mainly composed of clay in PLN (Ding et al., 2014), and the water level fluctuations are extremely large. These two species therefore tend to have only limited distribution. Before the summer flood in 1998, a small number of Najas plants may have completed flowering and fruiting, thereby supplementing the seed bank, aiding survival after the flood, despite the reduction in biomass. However, following the drought in spring 2011, most Najas seedlings were probably killed, preventing replenishment of the seed bank and resulting in extinction.

The changes in species number in the five sub-lakes may also suggest that drought has a more damaging effect on aquatic plants. After the flood in 1999, the species number in all sub-lakes, except Banghu, was higher than after the drought in 2012 
(Figure 3). Banghu Lake did not completely dry up during the drought of 2011; therefore, the species number remained high in 2012. Meanwhile, Charaphyte emerged after both flooding and drought, although its dominance was very low. Studies in a number of temperate lakes suggest that Charaphyte is not only a pioneer species in the restoration of aquatic plants, but one of the main dominant species (Blindow, 1992; van den Berg et al., 1999). These findings suggest that the recovery process of aquatic plants in subtropical lakes is different from that in temperate lakes. Although Charaphyte can be a pioneer species under low light conditions, it has no real roots and is easily uprooted by wind and waves (Havens et al., 2004). Thus, since the water level fluctuations are frequent and extreme in PLN, it is thought to be difficult for Charaphyte to establish in large numbers.

The results of this study also suggest that the resilience ability of aquatic plants is higher after flooding than drought. The resilience ability was 0.10 and 0.70 in 1999 and 2001, and 0.04 and 0.12 in 2012 and 2014, respectively. This is thought to be related to the differing effects of flooding and drought. Although flooding destroys the aerial parts of aquatic plants, most underground parts remain; however, drought can have adverse effects both aboveground and underground. Nevertheless, compared with 1984 (Guan et al., 1987), the biomass after both events was much lower than the historical level of $2902 \mathrm{~g} / \mathrm{m}^{2}$, suggesting that full recovery is difficult in the short term. However, no obvious differences in the restoration of aquatic plants were observed with increasing mean lake bottom elevation of the five sub-lakes. Although lake bottom elevation can significantly affect infiltration between sub-lakes and adjacent water bodies, the sediment type and distance from adjacent water also play important roles (Van Geest et al., 2005). In general, sub-lakes with sandy sediment and close to the main area of Poyang Lake experience larger water level fluctuations. Moreover, human disturbances, such as fishing during the flooding season, also affect the restoration of aquatic plants in different sub-lakes.

Obvious differences in the recovery rate of different species after flooding and drought were observed. Vallisneria spp. and $H$. verticillata were fastest to recover after flooding. Li et al. (2004) suggested that this is largely related to asexual reproduction. That is, although flooding caused the disappearance of aboveground parts, it had little effect on asexual propagules in the lake sediment; therefore, species possessing specialized propagules or underground rhizomes recovered rapidly. Of the nine aquatic plants that existed in the normal hydrological year of 1984, Vallisneria spp., $H$. verticillata and $P$. malaianus were not only rich in biomass, but also possess specialized vegetative propagules or underground stems, aiding recovery after flooding. However, in the 1999 and 2001 field surveys, the P. malaianus biomass was extremely low after flooding, possibly due to its small population size before flooding (Cui et al., 2000). The first species to recover after drought were Vallisneria spp. and N. peltata, but the biomass of both species was lower than historical levels. This was possibly due to the effect of drought on underground parts, which is also related to their burial depth. Vallisneria spp. and $N$. peltata could therefore be considered pioneer species, with recovery aided by the deep burial depth of their underground parts. In line with this, studies suggest that the burial depth of Vallisneria spp. winter buds can reach $30 \mathrm{~cm}$, while that of $P$. malaianus underground stems is only $10 \mathrm{~cm}$ (Li et al., 2005). In addition, $N$. peltata is an amphibious species that is more resistant to drought than submerged plants (Brock and Casanova, 1997), providing further advantages for the establishment of its dominant position. 
The analyses of dominant species further suggest that extreme hydrological events also have a significant impact on succession. As part of Poyang Lake, PLN experiences large water level fluctuations, and therefore, the species composition and dominant species are relatively simple. In 1984, the dominant species were Vallisneria spp. and P. malaianus (Guan et al., 1987), both of which have flexible aboveground parts that allow them to adapt to fluctuating water levels and strong wave disturbances. After flooding, $H$. verticillata replaced $P$. malaianus as one of the main dominant species; however, due to the lower burial depth of its asexual propagules, its dominance status was replaced by $N$. peltata.

The results of this study also suggest that the resilience ability of aquatic plants is higher after flooding than drought. Nevertheless, compared with 1984 (Guan et al., 1987), the biomass after both events was much lower than the historical level of $2902 \mathrm{~g} / \mathrm{m}^{2}$, suggesting that full recovery is difficult in the short term. As one of the most important wetlands in the world, Poyang Lake plays important roles in biodiversity conservation. With the increasing occurrence frequency and magnitude of extreme hydrological events in Poyang Lake basin (Ye et al., 2014), it is therefore necessary to implement effective measures to prevent further degradation of aquatic vegetation. In the future, experiments should be carried out to determine the tolerance thresholds of dominant aquatic plants such as Vallisneria spp. and $P$. malaianus in response to drought and flooding to provide a quantitative basis for the recovery of aquatic plants. Besides, compared with flooding, drought had more destructive effects; however, it is relatively easier to control. Strengthening the regulation of water resources should be considered to reduce the adverse effects of drought on dominant aquatic plants (such as Vallisneria spp.). At present, there are a number of small water conservation projects in the Poyang Lake basin, with plans to build Poyang Lake dam in the foreseeable future, which will further help regulate water levels in PLN. This study also suggests that aquatic plants are generally slow to recover after extreme hydrological events, highlighting the need for artificial methods aimed at supplementing seed banks or propagules to promote recovery.

\section{Conclusion}

The species composition and subsequent recovery process of lake plants after extreme flooding and drought are obviously different in the PLN. In general, extreme drought is more damaging to lake plants than extreme flooding. Therefore, the lakes should maintain a minimum water level in dry year through rational regulation of water resources to prevent the degradation of lake plants. Besides, the resilience ability of aquatic plants was higher after extreme flooding than following extreme drought; however, artificial methods aimed at supplementing seed banks or propagules are also needed to promote the recovery of aquatic plants in a short time. Finally, it is highly recommened that future researches carry out more studies to determine the tolerance thresholds of dominant aquatic plants (such as Vallisneria spp. and P. Malaianus in this study) in response to drought and flooding, thus providing a quantitative basis for the recovery of aquatic plants.

Acknowledgements. This work was supported by the National Natural Science Foundation of China (grant numbers 41501028, 51579234, and 41371054). 


\section{REFERENCES}

[1] Blindow, I. (1992): Long and short term dynamics of submerged macrophytes in two shallow lakes. - Freshwater Biology 28: 15-27.

[2] Brock, M. A., Casanova, M. T. (1997): Plant Life at the Edge of Wetlands: Ecological Responses to Wetting and Drying Patterns. - In: Klomp, N., Lunt, I. (eds.) Frontiers in Ecology: Building the Links. Elsevier, Oxford.

[3] Chen, H. D. (1984): Study on Najas major All. community of Lake Donghu, Wuhan. Acta Hydrobiologica Sinica 8: 331-340.

[4] Cui, X. H., Zhong, Y., Li, W., Chen, J. K. (2000): The effect of catastrophic flood on biomass and density of three dominant aquatic plant species in the Poyang Lake. - Acta Hydrobiologica Sinica 24: 322-325.

[5] Ding, Q. Z., Liu, X. Q., Zhang, X. K. (2014): Impacts of water level fluctuations on substrate environments of lakeshore zone of the lakes in the middle and lower reaches of the Yangtze River. - Journal of Lake Science 26: 340-348.

[6] Guan, S. F., Lang, Q., Zhang, B. (1987): Biomass of macrophytes of the Poyang Lake with suggestions of its rational exploitation. - Acta Hydrobiologica Sinica 11: 219-227.

[7] Handley, R. J., Davy, A. (2005): Temperature effects on seed maturity and dormancy cycles in an aquatic annual, Najas marina, at the edge of its range. - Journal of Ecology 93: 1185-1193.

[8] Havens, K. E., Sharfstein, B., Brady, M. A., East, T. L., Harwell, M. C., Maki, R. P., Rodusky, A. J. (2004): Recovery of submerged plants from high water stress in a large subtropical lake in Florida, USA. - Aquatic Botany 78: 67-82.

[9] Hoffmann, M., Sacher, M., Lehner, S., Raeder, U., Melzer, A. (2013): Influence of sediment on the growth of the invasive macrophyte Najas marina ssp. intermedia in lakes. - Limnologica 43: 265-271.

[10] Jentsch, A., Kreyling, J., Berierkuhnlein, C. (2007): A new generation of climate change experiments: events, not trends. - Frontiers in Ecology and the Environment 5: 315-324.

[11] Ji, W., Zeng, N., Wang, Y., Gong, P., Xu, B., Bao, S. (2007): Analysis on the waterbirds community survey of Poyang Lake in winter. - Geographic Information Sciences 13: 5164.

[12] Lake, P. S. (2007): Flow-generated Disturbances and Ecological Responses: Floods and Droughts. - In: Wood, P. J., Hannah, D. M., Sadler, J. P. (eds.) Hydroecology and Ecohydrology: Past, Present and Future. John Wiley \& Sons Ltd, Chichester.

[13] Li, W., Liu, G. H., Xiong, B. H., Pu, Y. H. (2004): The restoration of aquatic vegetation in lakes of Poyang Lake Nature Reserve after catastrophic flooding in 1998. - Journal of Wuhan Botanical Research 22: 301-306.

[14] Li, W., Cheng, Y., Liu, G. H. (2005): Resource and Environmental Characteristics of the Poyang Lake, a Large Lake Interconnected with the Changjiang River-Aquatic macrophytes. - In: Cui, Y. B., Li, Z. J. (eds.) Fishery Resources and Conservation of Environment in Lakes of the Changjiang River Basin. Science Press, Beijing.

[15] Li, H., Li, C. A., Zhang, L. H., Tian, L. Q. (2008): Relationship between water level and water area in Poyang Lake based on MODIS image. - Quaternary Sciences 28: 332-337.

[16] Li, M., Chai, X., Wang, G., Hu, W., Zhang, L. (2019): Research on meteorological drought in the middle and lower reaches of the Yangtze Rive. - Journal of Natural Resources 34(2): 374-384.

[17] Lu, B., Cheng, S. C. (2003): An analysis of the ecological environment of the Poyang Lake Nature Preservation Zone. - Transactions of Oceanology and Limnology 3: 35-42.

[18] Lytle, D. A., Poff, N. L. (2004): Adaption to natural flow regimes. - Trends in Ecology and Evolution 19: 94-100.

[19] Meehl, G. A., Stocker, T. F., Collins, W., Friedlingstein, P., Gaye, A., Gregory, J. (2007): Global Climate Projections. - In: Solomon, S., Qin, D., Manning, M., Chen, Z., Marquis, M., Averyt, K. B., Tignor, M. M. B., Miller, H. L. Jr. (eds.) Climate Change 2007: the 
Physical Science Basis. Contribution of Working Group I to the Fourth Assessment Report of the Intergovernmental Panelon Climate Change. Cambridge University Press, Cambridge and New York.

[20] Miao, S. L., Zou, C. B., Breshears, D. D. (2009): Vegetation responses to extreme hydrological events: sequence matters. - The American Naturalist 173: 113-118.

[21] Min, Q., Liu, Y., Ma, D. (2006): Impact of restoring lake by stopping cultivation on flood control capacity of Poyang Lake. - Resources and Environment in the Yangtze Basin 15(5): 574-578.

[22] Van den Berg, M. S., Scheffer, M., van Nes, E., Coops, H. (1999): Dynamics and stability of Chara sp. and Potamogeton pecutinatus in a shallow lake changing in eutrophication level. - Hydrobiologia 408/409: 335-342.

[23] Van Geest, G. J., Coops, H., Roijackers, R. M. M., Buijse, A. D., Scheffer, M. (2005): Succession of aquatic vegetation driven by reduced water-level fluctuations in floodplain lakes. - Journal of Applied Ecology 42: 251-260.

[24] Wang, S. M., Dou, H. S. (1998): Lakes of China. Science Press, Beijing.

[25] Xu, Z. M., Hu, W. Z., You, Z. Q. (2014): Analysis of low flow situation of Poyang Lake area after operation of Three Gorges Reservoir and its causes. - Yangtze River 45(7): 1822.

[26] Ye, C., Wu, G. P., Zhao, X. S., Wang, X. L., Liu, Y. B. (2014): Responses of wetland vegetation to droughts and its impact factors in Poyang Lake National Nature Reserve. Journal of Lake Science 26(2): 253-259.

[27] Zhang, L., Du, H., Jun, X., Xu, X. (2011): Progress in the study of extreme hydrologic events under climate change. - Progress in Geography 30(11): 1370-1379.

[28] Zhang, X. (2013): Water level fluctuation requirements of plants in the Yangtze floodplain lakes. - Ph.D. Thesis of University of Chinese Academy of Science, Beijing, China. 